\title{
Analisa Kalibrasi Kamera Sony Exmor Pada Nilai Orientasi Parameter Interior untuk Keperluan Pemetaan (FUFK)
}

\author{
Mohammad Avicenna, Agung Budi Cahyono, dan Husnul Hidayat \\ Departemen Teknik Geomatika, Fakultas Teknik Sipil Lingkungan dan Kebumian, \\ Institut Teknologi Sepuluh Nopember (ITS) \\ e-mail:hidayathusnul.nzl@gmail.com
}

\begin{abstract}
Abstrak-Berkembangnya teknologi Rapid Mapping dengan menggunakan wahana tanpa awak (UAV) menjadi salah satu metode penting saat ini. Namun penggunaan UAV khususnya seperti drone memiliki kelemahan dalam memperoleh hasil yang baik, karena sifat dari kamera non metrik. Oleh karena itu diperlukan kalibrasi kamera untuk memperoleh nilai parameter interior pada kamera. Kalibrasi pada penelitian ini dilakukan dengan 2 metode yaitu, kalibrasi In-Field dan kalibrasi In-Flight. Pada penelitian ini dilakukan analisa kalibrasi In-Field menggunakan marker/grid dengan 12 orientasi pengambilan foto pada saat posisi kamera drone stabil dan tidak dalam keadaan terbang. Data yang dihasilkan berupa 7 parameter IOP dengan hasil RMS 0.48 pixel. Hasil parameter dari kalibrasi In-Field ini akan digunakan pada kalibrasi InFlight sebagai perbandingan nilai IOP dengan menggunakan software Australis ${ }^{\circledR}$, setelah itu dilakukan analisa titik sampling foto udara dengan pengukuran terestris menggunakan Total Station. Data yang dihasilkan berupa parameter yang berasal dari kalibrasi In-Field, sehingga terjadinya perubahan nilai IOP. Nilai parameter yang dihasilkan menjadi 13 parameter dengan RMS 0,56 pixel. Kedua metode kalibrasi kamera tersebut diolah dengan menggunakan menggunakan bundle adjustment self-calibration. Hasil penelitian ini menunjukan bahwa kamera non-metrik Sony Exmor dapat digunakan untuk melakukan pemetaan dengan skala besar dengan area yang relatif kecil (FUFK) dengan acuan akurasi horizontal pada peta dasar yang berada pada Perka BIG No.15 tahun 2014, dengan nilai RMS yang dihasilkan sebesar $0.159 \mathrm{~m}$.
\end{abstract}

Kata Kunci-Kalibrasi Kamera, kalibrasi In-Field dan kalibrasi In-Flight, Interior Orientation Parameter, Distorsi Kamera.

\section{PENDAHULUAN}

$\mathrm{T}$ ERMINOLOGI baru menggunakan pesawat tanpa awak atau yang bias a disebut UAV (Unmanned Aerial Vehicle) merupakan platform yang mendukung untuk pengukuran fotogrametri. Saat ini UAV banyak sekali digunakannya untukpemetaan rapid mapping untuk keperluan peta dengan area yang relatif kecil atau Foto Udara Format Kecil (FUFK). Foto udara Format Kecil dengan menggunakan UAV ini memiliki beberapa keunggulan, yaitu dalam hal biaya operasional yang murah, peralatan mudah diperoleh, serta cepat dalam memperoleh data, namun untuk FUFK dengan menggunakan UAV ini memiliki kelemahan utama pada sistem pencitraan atau sistem kameranya yang menggunakan kamera non metric [1]. Sistem kamera foto udara sangat potensial memiliki distorsi geometrik dan ketidakstabilan parameter instrinsik kamera [2]. Kalibrasi kamera non-metrik pada UAV yang tidak stabil ini akan menimbulkan distorsi geometrik ketika melakukan pemotretan disetiap lokasi yang berbeda baik itu dilaboratorium dan dilapangan [3].

Oleh karena itu untuk meminimalisir kelemahan pada kamera non-metrik maka dilakukan kalibrasi. Pada penelitian ini dilakukan kalibrasi kamera dengan 2 metode yaitu kalibrasi In-Field menggunakan sofware Photomodeler Scanner dan kalibrasi In-Flight menggunakan software Australis ${ }^{\circledR}$ dengan menggunakan bundle adjustment selfcalibration. Dengan menggunakan metode ini dapat diketahui distorsiradial yang dihasilkan pada masing-masing kalibrasi, sehingga hasil dari distorsi tersebut dapat mengetahui posisi pergeseran linier titik foto dalam arah radial terhadap titik utama dari posisi ideal dan juga menandakan stabil atau tidaknya suatu kamera non-metrik yang digunakan untuk pemetaan Foto Udara Format Kecil (FUFK).

\section{METODOLOGI PENELITIAN}

\section{A. Lokasi Penelitian}

Lokasi penelitian ini dilakukan di kampus ITS Surabaya. Adapun untuk metode kalibrasi In-Field dilakukan di laboratorium KKP (Kadaster Kebijakan Pertanahan) sedangkan untuk kalibrasi In-Flight dilakukan di lapangan voli ITS (FASOR).

\section{B. Data dan Peralatan}

Data yang dibutuhkan dalam penelitian ini adalah:

a. Data pengambilan foto grid pada kalibrasi In-Field dengan 12 orientasi sebanyak 3 kala dan data kalibrasi In-Flight dengan 9 orientasi foto sebanyak 1 kala.

b. Data pengukuran titik kontrol tanah sebanyak 25 buah.

Adapun untuk peralatan yang dibutuhkan dalam penelitian ini adalah:

1. Perangkat untuk mengolah data serta membuat laporan terdiri dari Laptop Asus X451CAP, Australis $8.25^{\circledR}$, Photomodeler Scanner (versi demo) dan microsoft office $2013^{\circledR}$.

2. Perangkat pengambilan data terdiri dari DJI Phantom 3 beserta kamera Sony Exmor, Total Station Serta Grid kalibrasi In-Field dan marker kalibrasi In-Flight.

C. Tahapan Pengolahan Data

Tahapan pengolahan data pada penelitian ini adalah sebagaiberikut: 


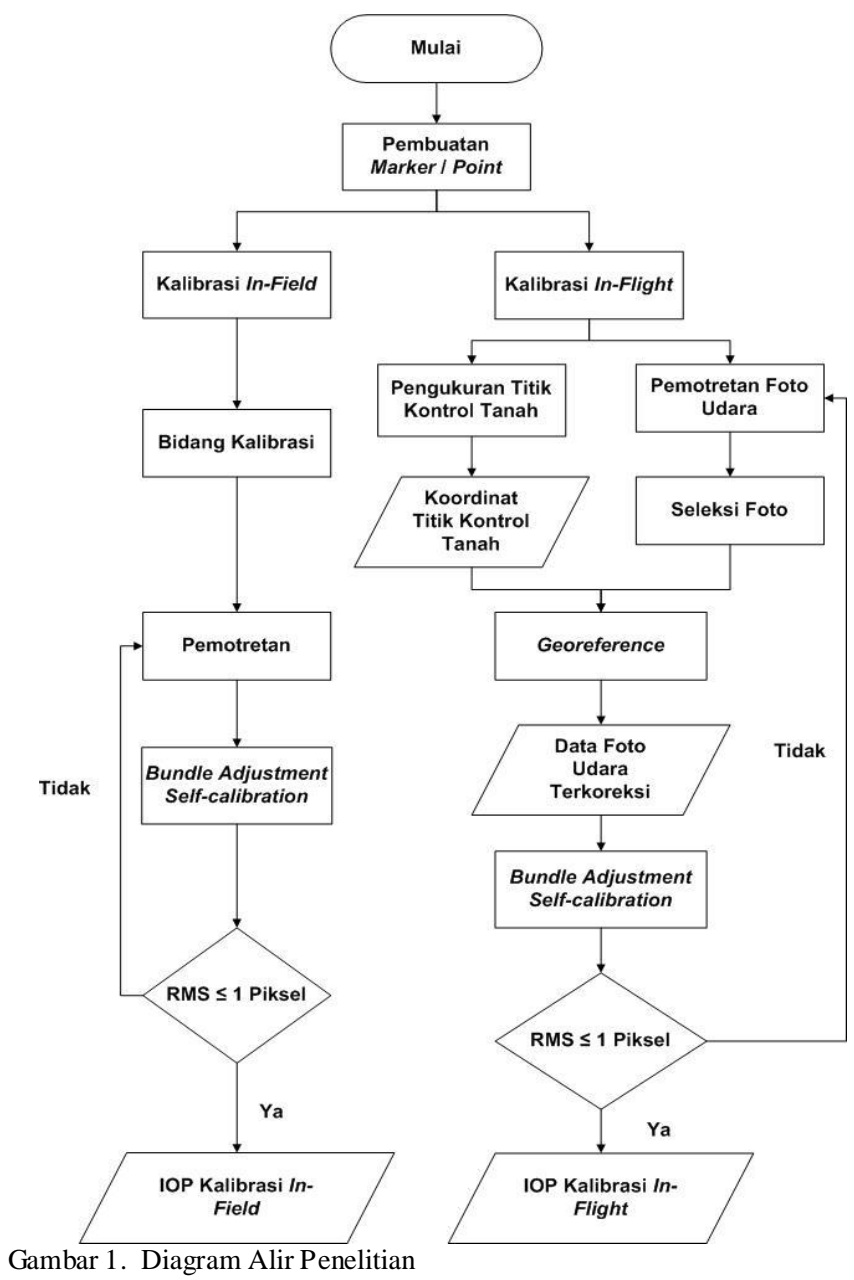

Penjelasan diagram alir di atas sebagai berikut.

1. Tahap Persiapan

Pada tahap ini dilakukan proses pengumpulan data berupa peta foto udara dan hasil pengukuran titik kontrol tanah.

2. Tahap Pengolahan

Pada tahapan ini dilakukan pengolahan dari data yang telah didapat di lapangan dan data penunjang lainnya. Data yang didapat dari laboratorium merupakan kalibrasi In-Field serta data yang di dapat dari lapangan berupa hasil pemotretan foto udara dan pengukuran titik sampling merupakan kalibrasi In-Flight. Kedua metode kalibrasi tersebut yang diolah dengan bundle adjustment selfcalibration.

3. Tahap Analisa

Dari pengolahan data yang dilakukan oleh 2 metode kalibrasi tersebut selanjutnya akan dilakukan analisa untuk mendapatkan nilai dari kalibrasi kamera, baik itu kalibrasi In-Field maupun kalibrasi In-Flight. Analisa data kalibrasi berupa IOP (Interior Orientation Parameter) yang berasal dari masing-masing metode, dimana kedua metode tersebut akan dibandingkan hasilnya. Apabila mendapakan nilai yang tidak terlalu besardiantara 2 metode tersebut maka nilai IOP yang dihasilkan cukup stabil/konstan dan kamera Sony Exmor tersebut dapat digunakan untuk rapid mapping.

4. Tahap Akhir
Pada tahap ini dilakukan penulisan laporan penelitian dari semua kegiatan penelitian yang telah dilakukan.

\section{HASIL DAN ANALIS IS}

A. Hasil

Analisa ini dilakukan terhadap hasil kalibrasi kamera Sony EXMOR pada nilai parameter Orientasi interior:

a) Kalibrasi In-Field

Hasil kalibrasi In-Field menggunakan media papan dengan format grid kalibrasi yang berasal dari software Photomodeller Scanner dimana hasilnya berupa parameter IOP (Interior Parameter Orientation). Parameter IOP tersebut terdiri dari fokus lensa (C) pusat fidusial foto (Xp, Yp), distorsi lensa radial (K1 dan $\mathrm{K} 2$ ), dan distorsi tangensial (P1 dan P2). Hasil kalibrasi In-Field ini akan digunakan untuk mengetahui nilai pembanding pada kalibrasi In-Flight, berikut hasil dari 3 kala kalibrasi :

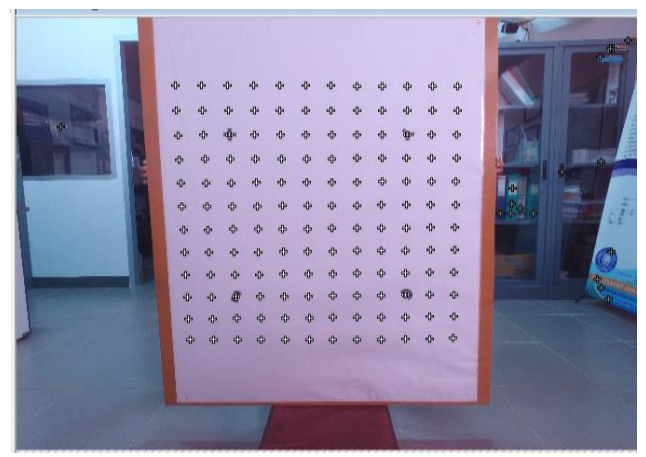

Gambar 2. Kalibrasi In-Field

Tabel 1

Hasil Kalibrasi In-Field

\begin{tabular}{cccr}
\hline \hline $\begin{array}{c}\text { Variable } \\
\text { IOP }\end{array}$ & Kala 1 & Kala 2 & Kala 3 \\
\hline $\mathrm{C}$ & $3.760 \mathrm{~mm}$ & $3.767 \mathrm{~mm}$ & $3.764 \mathrm{~mm}$ \\
$\mathrm{Xp}$ & $3.249 \mathrm{~mm}$ & $3.249 \mathrm{~mm}$ & $3.254 \mathrm{~mm}$ \\
Yp & $2.399 \mathrm{~mm}$ & $2.398 \mathrm{~mm}$ & $2.397 \mathrm{~mm}$ \\
K1 & $7,397 \mathrm{e}-004$ & $1.066 \mathrm{e}-003$ & $6.282 \mathrm{e}-004$ \\
K2 & $-4,159 \mathrm{e}-005$ & $-6.095 \mathrm{e}-005$ & $-8.357 \mathrm{e}-006$ \\
P1 & $2,978 \mathrm{e}-005$ & $1.852 \mathrm{e}-005$ & $-1.106 \mathrm{e}-004$ \\
P2 & $-5,791 \mathrm{e}-005$ & $-9.527 \mathrm{e}-005$ & $-6.930 \mathrm{e}-005$ \\
\hline \hline
\end{tabular}

Ketelitian yang dihasilkan dari 3 kala kalibrasi diatas masih memliki kekurangan dalam menghasilkan nilai yang sempurna, namun untuk hasil dari 3 kala ters ebut maka digunakan hasil yang mendekati nilai yang direkomendasikan yaitu terdapat pada kala 2 karena area foto yang tercakup $68 \%$ dari yang direkomendasikan sebesar $80 \%$, sehingga menghasilkan nilai RMS point residual sebesar 0.48 pixel dan point precision $0.375 \mathrm{~mm}$.

b) Kalibrasi In-Flight

Hasil kalibrasi In-Flight menggunakan papan kalibrasi berukuran $40 \mathrm{~cm}$ X $40 \mathrm{~cm}$ dengan dilapisi sebuah kertas hitam dan diberi stiker reflektor berdiameter $10 \mathrm{~cm}$ di posisi center pada papan tersebut. Kalibrasi ini diolah dengan menggunakan software Australis dimana hasilnya berupa parameter 
IOP dan menghasilkan parameter distorsi lensa baru berupa $(\mathrm{K} 3, \mathrm{~K} 4$, dan $\mathrm{K} 5)$ serta distorsi ketidakortogonalan X dan Y (B1, B2).
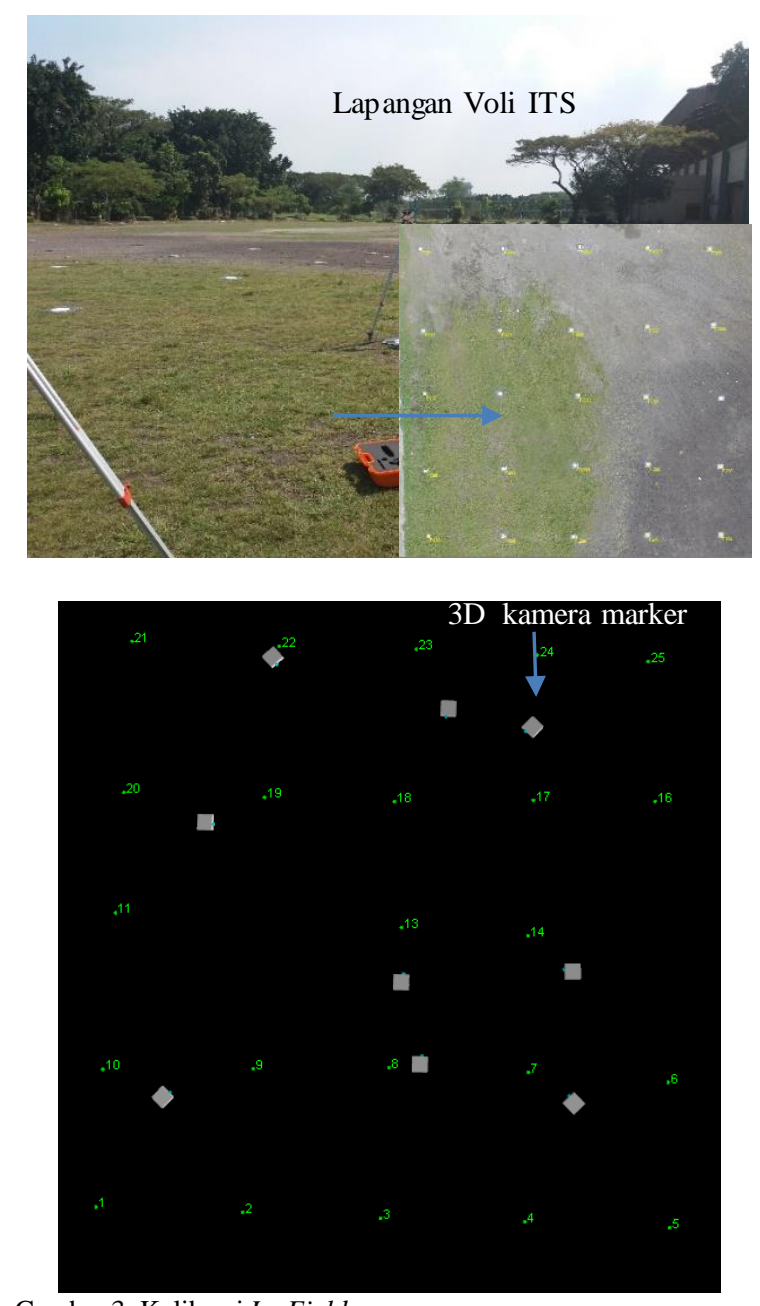

Gambar 3. Kalibrasi In-Field

Tabel 2

Hasil Kalibrasi In-Flight

\begin{tabular}{|c|c|}
\hline $\begin{array}{c}\text { Variabel } \\
\text { IOP }\end{array}$ & Value \\
\hline $\mathrm{C}$ & $4.012 \mathrm{~mm}$ \\
\hline $\mathrm{Xp}$ & $3,991 \mathrm{~mm}$ \\
\hline Yp & $1,637 \mathrm{~mm}$ \\
\hline K1 & $-1.42868 \mathrm{e}-04$ \\
\hline K2 & $8.65942 \mathrm{e}-06$ \\
\hline K3 & $-2.21741 \mathrm{e}-07$ \\
\hline K4 & $2.64106 \mathrm{e}-09$ \\
\hline K5 & $-1.16088 \mathrm{e}-11$ \\
\hline P1 & $-4.60783 e-05$ \\
\hline P2 & $-3.04106 e-04$ \\
\hline B1 & $-1.25159 \mathrm{e}-02$ \\
\hline B2 & $1.84932 \mathrm{e}-03$ \\
\hline
\end{tabular}

Ketelitian yang dihasilkan dari kalibrasi diatas masih memiliki kekurangan dalam menghasilkan nilai yang stabil terhadap kalibrasi In-Fligh, sehingga. Hasil kalibrasi In-Flight memiliki selisih dari setiap variabel parameter kalibrasi In-Field. Oleh karena itu dari perbedaan nilai 2 metode kalibrasi tersebut menghasilkan nilai Point Residual 0.56 pixel.

c) Georefencing

Sistem kesegarisan merupakan konsep dasar dari transformasi koordinat foto dengan koordinat tanah. Titik sampling yang ada pada hasil foto dan yang didapat melalui pengukuran terestris ini akan dilakukan Georefence, dimana titik sampling yang digunakan yaitu sistem koordinat lokal. Titik sampling lokal dimulai dengan $\mathrm{X}$ dan $\mathrm{Y}(0,0)$. Pada penelitian ini titik kontrol yang didapat melalui pengukuran terristris akan digunakan pada titik kontrol yang berada di hasil titik sampling foto udara. Titik sampling pada foto ditandai dengan sebuah marker. Setelah itu proses yang dilakukan yaitu mengubah orientasi foto pada sumbu $\mathrm{X}$ dan $\mathrm{Y}$ dengan kosep kolinierisasi. Sumbu X dan Y pada hasil foto sangat berpengaruh pada titik kontol yang dihasilkan karena dapat membuat posisi titik sampling yang ada di foto berbeda dengan yang ada pada pengukuran terestris.

Tabel 3

Selisih Nilai Titik Sampling TSdengan Foto

\begin{tabular}{ccc}
\hline \hline \multirow{2}{*}{ Titik Sampling } & \multicolumn{2}{c}{$\Delta$} \\
\cline { 2 - 3 } & $\mathrm{X}(\mathrm{m})$ & $\mathrm{Y}(\mathrm{m})$ \\
\hline 1 & 0,000 & 0,000 \\
3 & 0,035 & 0,032 \\
4 & 0,034 & 0,034 \\
5 & 0,039 & 0,034 \\
6 & 0,105 & 0,034 \\
7 & 0,054 & 0,030 \\
8 & 0,104 & 0,031 \\
9 & 0,035 & 0,032 \\
10 & 0,052 & 0,051 \\
11 & 0,031 & 0,096 \\
12 & 0,032 & 0,055 \\
13 & - & - \\
14 & 0,089 & 0,101 \\
15 & 0,054 & 0,057 \\
16 & - & - \\
17 & 0,118 & 0,187 \\
18 & 0,101 & 0,103 \\
19 & 0,080 & 0,106 \\
20 & 0,077 & 0,124 \\
21 & 0,038 & 0,084 \\
22 & 0,041 & 0,049 \\
23 & 0,060 & 0,047 \\
24 & 0,035 & 0,062 \\
25 & 0,051 & 0,081 \\
& 0,173 & 0,032 \\
\hline
\end{tabular}

Dari hasil selisih Total Station dengan foto dapat dianalisa bahwa titik sampling 12 dan 15 tidak terdeteksi saat pengolahan data foto pada kalibrasi In-Field dan terjadinya pergeseran terbesar pada titik sampling X sebesar $0.173 \mathrm{~m}$ dan $0.187 \mathrm{~m}$ pada titik sampling Y. Hal ini menunjukan bahwa pengolahan titik sampling yang ada pada foto dapat digunakan sebagai hasil pengukuran.

B. Analisa

1) Analisa data kalibrasi In-Flight dan In-Field

Tabel 4

Perbandingan Hasil Parameter Kalibrasi Kamera

\begin{tabular}{cr}
\hline \hline Variabel & $\Delta$ \\
IOP & $0,245 \mathrm{~mm}$ \\
C & $0.742 \mathrm{~mm}$ \\
Xp & $0.761 \mathrm{~mm}$ \\
Yp & 15,353 \\
K1 & 0,927 \\
K2 & 4,626 \\
P1 & 30,315 \\
P2
\end{tabular}

Dari hasil perbadingan diatas dapat dianalisa bahwa perubahan yang terjadi pada focal lenght $(\mathrm{C})$ relatif kecil dibandingkan dengan hasil titik pusat fidusial foto $(\mathrm{Xp}$ 
,Yp) serta distorsi lensa (K1,K2,P1 dan P2) yang memiliki selisih besar, sehingga mempengaruhi pergeseran lokasi titik yang ada pada foto dari kondisi sebenarnya di lapangan. Faktor lain yang mempengaruhi dalam hal tersebut yaitu dengan menggunakan sistem fokus kamera foto tidak berubah saat pengambilan, maka dapat diambil beberapa faktor yang mempengaruhi hasil perubahan nilai parameter kalibrsi In-Field dan kalibrasi In-Flight, yaitu [4]:

1) Objek kalibrasi.

Penggunaan objek kalibrasi yang kurang sesuai dengan daerah/objek yang akan di ukur akan berpengaruh terhadap hasil pengukuran. Pada penelitian kalibrasi In-Field ini dilakukan dengan menggunakan bidang kalibrasi dengan format grid/marker yang ada pada software karena sofware tersebut hanya membaca marker dengan ketentuan tersebut dan pada penelitian kalibrasi In-Flight dilakukan dengan menggunakan papan kayu kecil sebagai marker, dimana luas lahan yang tidak seragam dengan ukuran bidang kalibrasi membuat marker/objek kalibrasi tidak terlihat, untuk meminimalisir hal tersebut maka pemilihan objek yang memiliki dimensi fisik mendekati daerah/objek yang akan diukur.

2) Geometri Pemotretan.

Geometri pemotretan kalibrasi akan sangat berpengaruh terhadap hasil perubahan nilai parameterkalibrasi kamera, agar parameter kalibras i kamera tidak saling berkorelasi (Photomodeler Help File).

Untuk keperluan fotogrametri maka parameter internal kamera seharusnya stabil, sehingga dapat meningkatkan kualitas hasil hitungan. Maka penggunaan metode self calibration sangatlah tepat, karena dapat memperkecil resiko tidak stabilnya parameter internal kamera, sebab kamera akan dikalibrasi menggunakan data ukuran saat kamera itu digunakan [5]. Namun, untuk mendapatkan hasil self-calibration yang baik, dibutuhkan konfigurasi jaring stasiun pemotretan yang sangat konvergen dan sebaran titik yang baik (menyebar), dan pelaksanaan di lapangan tidak selalu menjamin didapatkannya geometri terbaik ${ }^{[8]}$. Oleh karena itu baiknya kalibrasi dilakukan sebelum pengukuran yang sebenarnya dan menggunakan objek yang sesuai.

2) Analisa pengolahan data

a. Analisa Presisi Data Titik Sampling dari Foto

Analisis didasarkan oleh hasil bundle adjustment dari software Australis. Jumlah titik yang diolah sebanyak 25 titik, namun titik yang berhasil diolah berjumlah 23 titik. Rata-rata sigma untuk tiap titik adalah $0.063 \mathrm{~m}$ ke arah X dan $0.064 \mathrm{~m}$ ke arah Y .Hasil ini sesuai dengan asumsi bahwa untukpengukuran kalibrasi InField ketelitian kearah $\mathrm{Y}$ akan lebih jelek dibandingkan pengukuran ke arah X. Ini karena pada metode kalibrasi In-Field arah $\mathrm{Y}$ adalah jarak pemotretan sebanding dengan arah $\mathrm{Z}$ pada fotogrametri udara. Dari hasil pengolahan bundle adjustment dapat dikatakan hasil pengolahan foto menunjukan hasil yang presisi.

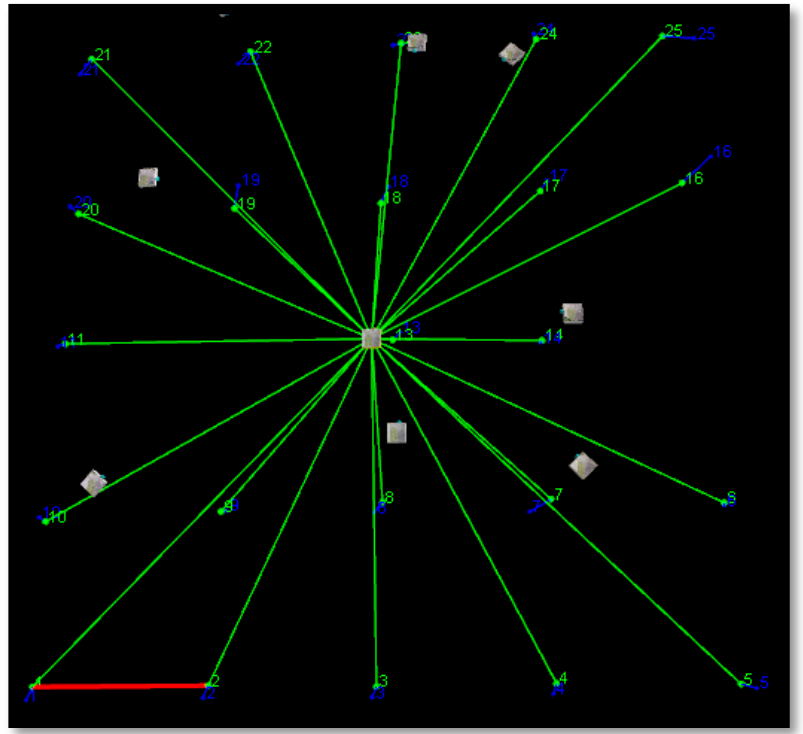

Gambar 4. Pergeseran Titik Sampling Foto Terhadap Titik Sampling tanah

b. Analisa Akurasi Data Titik Sampling dari Foto

Tingkat akurasi koordinat hasil pengolahan foto dapat dilihat dengan menghitung kesalahan terhadap data koordinat dari ukuran Total Station. Nilai koordinat dari data Total Station diasumsikan sebagainilai yang benar. Besar kesalahan dihitung dengan menggunakan RMS data pengukuran Total Station dan diperoleh RMS 0,104 m. Tingkat keakurasian ini dapat dibandingkan dengan resolusi spasial dari kamera. Resolusi spasial adalah kemampuan sensor kamera untuk mendeteksi objek terkecil. Resolusi spasial kamera dapat dihitung menggunakan perbandingan sebagai berikut:

$$
\frac{p}{c}=\frac{r}{D}
$$

$$
\begin{aligned}
& \mathrm{p}=\text { ukuran sensor } \\
& \mathrm{c}=\text { panjang fokus } \\
& \mathrm{D}=\text { Jarak kamera terhadap objek } \\
& \mathrm{r}=\text { resolusi spasial }
\end{aligned}
$$

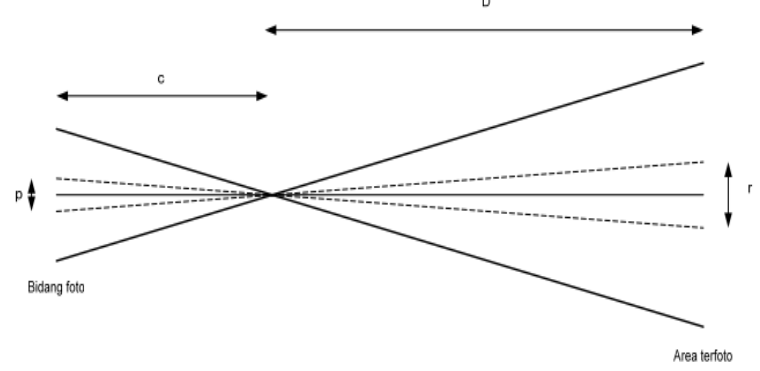

Gambar 4. Perbandingan resolusi kamera dengan ukuran senor [1].

Kamera Sony Exmor yang digunakan memiliki ukuran sensor sebesar $0.110 \mathrm{~mm}$, dengan jarak fokus $4 \mathrm{~mm}$. Jika rata-rata jarak pemotretan adalah $10 \mathrm{~m}$, maka resolusi spasial yang diharapkan adalah $0.275 \mathrm{~m}$

3) Analisa Geometri Menurut Perka BIG

Pedoman yang digunakan dalam pengujian ketelitian geometri adalah Perka BIG Nomor 15 Tahun 2014 Tentang Pedoman Teknis Ketelitian Peta Dasar. 


$$
\begin{aligned}
& \text { RMSE } x=\sqrt{\frac{\sum\left(X_{\text {Image }}-X_{\text {Lapangan }}\right.}{n}} \\
& \text { RMSE } y=\sqrt{\frac{\sum\left(Y_{\text {Image }}-Y_{\text {Lapangan }}\right.}{n}} \\
& \text { RMSE }=\sqrt{R M S E x^{2}+R M S E y^{2}}
\end{aligned}
$$

\section{Akurasi Horizontal NMAS $=1,5175 \times$ RMSEr Akurasi Vertikal NMAS $=1,6499 \times$ RMSEz}

Dari penelitian yang telah dialakukan maka didapat RMSe sebesar $0.104 \mathrm{~m}$ dengan RMSEx $0.073 \mathrm{~m}$ dan RMSEy $0.075 \mathrm{~m}$. Menurut ketentuan perka BIG tersebut maka hasil pengukuran dengan menggunakan DJI Phantom 3 Advance dengan kamera Sony Exmor

\begin{tabular}{|c|c|c|c|c|c|c|c|c|}
\hline \multirow[b]{3}{*}{ No } & \multirow{3}{*}{ Shala } & \multirow{3}{*}{$\begin{array}{c}\text { Interval } \\
\text { Kontur } \\
\text { (m) }\end{array}$} & \multicolumn{6}{|c|}{ Ketelitian Pecta RBI } \\
\hline & & & \multicolumn{2}{|c|}{ Kelas I } & \multicolumn{2}{|c|}{ Kelas 2} & \multicolumn{2}{|c|}{ Kelas 3} \\
\hline & & & $\begin{array}{l}\text { Horizontal } \\
\text { (CE90 } \\
\text { dalam m) }\end{array}$ & $\begin{array}{c}\text { Vertikal } \\
\text { (LE90 } \\
\text { dalam m) }\end{array}$ & $\begin{array}{c}\text { Horizontal } \\
\text { (CE90 } \\
\text { dalam m) }\end{array}$ & $\begin{array}{c}\text { Vertikal } \\
\text { (LE90 } \\
\text { dalam m) }\end{array}$ & $\begin{array}{c}\text { Horizontal } \\
\text { (CE90 } \\
\text { delmm m) }\end{array}$ & $\begin{array}{c}\text { Vetrikal } \\
\text { (LE90 } \\
\text { delam m) }\end{array}$ \\
\hline 1 & 1:1.000000 & 400 & 200 & 200 & 300 & 300 & 500 & 500 \\
\hline 2 & 15500.000 & 200 & 100 & 100 & 150 & 150 & 250 & 250 \\
\hline 3 & $1: 250.000$ & 100 & 50 & 50 & 75 & 75 & 125 & 125 \\
\hline 4 & 1:100.000 & 40 & 20 & 20 & 30 & 30 & 50 & 50 \\
\hline 5 & 1:50.000 & 20 & 10 & 10 & 15 & 15 & 25 & 25 \\
\hline 6 & $1: 25.000$ & 10 & 5 & 5 & 7,5 & 7,5 & 12,5 & 12,5 \\
\hline 7 & 1.10 .000 & 4 & 2 & 2 & 3 & 3 & 5 & 5 \\
\hline 8 & 1.5 .000 & 2 & 1 & 1 & 1,5 & 1,5 & 2,5 & 2,5 \\
\hline 9 & $1: 2.500$ & I & 0,5 & 0,5 & 0,75 & 0,75 & 1,25 & 1,25 \\
\hline 10 & 1:1,000 & 0,4 & 0,2 & 0,2 & 0,3 & 0,3 & 0,5 & 0,5 \\
\hline
\end{tabular}
menghasilkan akurasi horizontal sebesar $0.159 \mathrm{~m}$ dan berada dalam kelas 1 dengan skala besar 1:1000.

Gambar 5. Ketelitian Peta Dasar

\section{KESIMPULAN}

Kesimpulan dari penelitian yang telah dilakukan ini yaitu :

1. Berdasarkan pengambilan data kalibrasi In-Field dan kalibrasi In-Flight terdapat perbedaan hasil
IOP yang relatif kecil pada panjang fokus kamera sehingga dapat disimpulkan bahwa kamera Sony Exmor dapat digunakan untuk pemetaan skala besar untuk akurasi pada nilai horizontal yang menghasilkan RMS $0.159 \mathrm{~m}$ dengan acuan Perka BIG No.15 tahun 2014, dimana skala besarters but masuk dalam kelas 1 dengan skala 1:1000.

2. Terdapat selisih nilai dari hasil IOP (Interior Orientation Parameter) pada panjang fokus (C) kamera untuk kalibrasi In-Field sebesar 0,256 mm terhadap hasil kalibrasi In-Flight, hal ini menunjukan bahwa terjadinya perubahan ukuran principle point (Xp, Yp).

3. Jarak distorsiradial yang dihasilkan oleh kalibras $\mathrm{i}$ In-Field sebesar $0.375 \mathrm{~mm}$ dan kalibrasi In-Flight sebesar $7.8 \mathrm{~mm}$, hal ini berdampak pada perubahan nilai variabel IOP besar khususnya distorsi lensa radial (K1) dan tangensial (P2).

4. Pergeseran linier koordinat foto terhadap koordinat tanah rata-rata untuk tiap titik adalah $0.063 \mathrm{~m}$ ke arah X dan $0.064 \mathrm{~m}$ ke arah Y sehingga menghasilkan RMSe terhadap koordinat X: 0,073 m dan RMS terhadap Y: 0,075 m. Hal ini sebabkan pada geometri posisipengambilan foto udara yang kurang baik, pengambilan foto kurang pencahayaan dan warna background peletakan marker harus sewarna.

\section{DAFTAR PUSTAKA}

[1] N. Hanifa, "Studi Pengunaan Kamera Digital Low-Cost NonMetric Auto Focus untuk Pemantauan Deformasi," Bandung 2007.

[2] Atkinson, Close Range Photogrammetry and Machine Vision. United Kingdom: Whittles Publishing, 1996.

[3] E. Honkavaara, "In-flight Camera Calibration for Direct Georeferencing," Finlandia, 2004.

[4] A. Kusumadarma, "Aplikasi Close Range Photogrametry dalam Pemet aan Bangunan Rekayasa dengan Kamera Digital Non-metrik terkalibrasi,"'Bandung, 2008.

[5] E. Merrit, "Field Camera Calibration," Photogramm. Eng. Rec., vol. 17 , no. 4, pp. 611-535, 1948. 